\title{
Strategi Promosi Bali Treetop Adventure Park Di Kebun Raya Eka Karya Bali, Bedugul, Kabupaten Tabanan
}

Aulia Azzahra a, 1, Luh Putu Kerti Pujani a, 2

1aazahra116@gmail.com,2kerti_pujani@unud.ac.id

a Program Studi S1 Destinasi Pariwisata, Fakultas Pariwisata,Universitas Udayana, Jl. Dr. R. Goris, Denpasar, Bali 80232 Indonesia

\section{Abstract}

The tourism sector contributes a lot to the economic development in Indonesia, it can be seen from the number of new job opening, increasing the income of the state and increasing the economy of the people around the tourist destination. However, in its development, tourism has also experienced many problems, such as the increasingly tight competition among Southeast Asian countries in controlling the world tourism market target to make its region as the world's main tourist destination in the region. A poorly-organized marketing strategy can be a major problem in market target. It happened at the outbound tourist attraction of Bali Treetop Adventure Park located at Eka Karya Bali Botanical Garden, Bedugul, Tabanan Regency. Many tourists do not know the attraction of this outbound tour. This is due to lack of information for tourists about the tourist attraction, a less precise marketing strategy is suspected to be the main problem.

The purpose of this research is to find out the marketing strategy of Bali Treetop Adventure Park at Eka Karya Bali Botanical Garden, Bedugul, Tabanan Regency. Types of data that is used are qualitative data and quantitative data with approaches through observation, interviews, questionnaires distribution to tourists, literature study and documentation. The data analyzed in the research is the explanation of various explanations of data obtained directly from the managers of Bali Treetop Adventure Park and tourists during this research took place.

The result of this research is Bali Treetop Adventure Park has several marketing strategies that is direct promotion (sales call, exhibition, brochure), promotion of mass media (magazine, baliho, Facebook, YouTube), indirect promotion (travel agent and local guide). The target of the market has been obtained but it is not maximized, this is caused by the market strategies which is not done properly. So it is necessary to improve its performance for human resources in the tourist attraction of Bali Treetop Adventure Park is to achieve the desired number of tourists visit.

\section{Keywords : outbond, tourist attractions, treetop}

\section{PENDAHULUAN}

Pariwisata sebagai salah satu industri dunia mampu meningkatkan devisa pada suatu negara, termasuk Indonesia. Pada tahun 2015, pariwisata menempati urutan ke-4 perolehan devisa Indonesia dengan jumlah nilai US\$ 12,5 juta setelah minyak \& gas bumi, batu bara, dan minyak kelapa sawit (Pitana, 2016). Keindahan alam serta keragaman budaya menjadi faktor majunya sektor pariwisata di Indonesia dan Bali pada khususnya. Angka kunjungan wisatawan ke Bali juga cenderung meningkat setiap tahunnya. Pada tahun 2015, tercatat jumlah wisatawan mancanegara ke Bali mengalami peningkatan sebesar $6,24 \%$ dari tahun 2014. Sedangkan jumlah wisatawan nusantara ke Bali angka peningkatannya sebesar 11,77\% (Pitana, 2016).

Meningkatnya jumlah wisatawan yang datang ke Bali tentu juga menimbulkan permintaan pariwisata yang semakin bertambah. Permintaan yang dimaksud adalah preferensi masing-masing wisatawan yang berbeda-beda. Hal tersebut menyebabkan para pengembang pariwisata untuk berpikir kreatif dalam mengemas wisata yang ditawarkan. Oleh karena itu sekarang telah tersedia berbagai macam paket wisata di Bali yang ditawarkan untuk wisatawan baik lokal maupun asing. Dalam penelitian ini akan dibahas mengenai adventure tourism atau wisata petualangan sebagai salah satu jenis wisata yang ditawarkan.

Weaver (2001) menjelaskan bahwa "adventure tourism merupakan wisata yang menitikberatkan pada kegiatan yang beresiko, menantang fisik, sehingga wisatawan harus memiliki kemampuan tertentu". Adventure tourism juga termasuk ke dalam alternative tourism atau pariwisata minat khusus. Adanya adventure tourism juga menjadi variasi dari keberagaman jenis pariwisata yang dapat ditawarkan menjadi suatu paket wisata untuk memenuhi permintaan wisatawan.

Berbagai jenis paket wisata yang ditawarkan juga harus memiliki daya saing yang tinggi dan bersifat variatif. Wisatawan dalam hal ini sebagai konsumen jelas akan memilih paket yang dianggap paling baik di 
antara lainnya namun juga selalu memperhitungkan anggaran yang mereka keluarkan. Hasan (2015) menjelaskan bahwa "harga sebagai salah satu indikator daya saing produk perlu ditetapkan secara matang agar konsisten sejak awal hingga suatu saat tertentu ketika harga harus diubah". Namun jika produk dan harga telah disusun dengan baik, tentu tidak akan dapat langsung dibeli oleh konsumen tanpa adanya promosi.

Hasan (2015) juga mengatakan bahwa "promosi merupakan variabel khusus pemasaran untuk menarik perhatian wisatawan potensial ke destinasi tertentu dan menikmati berbagai kegiatan yang dirancang dalam pariwisata. Dalam konteks bisnis promosi dimaknai untuk menginformasikan, membujuk, dan mengingatkan wisatawan - baik secara langsung maupun tidak langsung - tentang suatu produk atau brand yang dijual kepada calon wisatawan". Dengan demikian, promosi bisa dianggap sebagai media yang menghubungkan antara produsen dengan konsumen dengan harapan terjadi transaksi antara kedua pihak tersebut.

Bali Treetop Adventure Park merupakan daya tarik wisata di Bali yang menawarkan berbagai atraksi wisata petualangan atau adventure tourism. Tempat ini dirancang untuk memacu adrenalin wisatawan yang memiliki minat untuk melakukan kegiatan secara fisik. Berdasarkan studi pendahuluan yang peneliti lakukan, banyak wisatawan yang mengetahui daya tarik wisata ini melalui media sosial. Tetapi media sosial bukan satu-satunya media untuk promosi. Ada media promosi lain yang dapat digunakan seperti iklan, promosi penjualan, Word of Mouth (WOM), dan lain-lain. Maka dari itu, penelitian ini dilakukan untuk mengetahui strategi promosi yang diterapkan oleh Bali Treetop Adventure Park di Kebun Raya Eka Karya Bali, Bedugul, Kabupaten Tabanan.

\section{TINJAUAN PUSTAKA}

Telaah hasil penelitian sebelumnya yang terkait dengan penelitian ini ada dua. Penelitian pertama bersumber dari sebuah laporan akhir dan berkaitan dengan fokus penelitian yang sama. Penelitian tersebut dilakukan oleh Zahro (2012) berjudul "Strategi Komunikasi Pemasaran Terpadu Desa Wisata dalam Meningkatkan Kunjungan Wisatawan
(Studi Deskriptif Kualitatif Pada Desa Wisata Kelor, Sleman, Yogyakarta)". Sedangkan penelitian kedua bersumber dari sebuah jurnal dengan lokus penelitian yang sama. Penelitian yang dimaksud dilakukan oleh Darma (2009) berjudul "Kebun Raya Eka Karya Bali, Konservasi dan Budaya dalam Harmoni".

Penelitian ini menggunakan beberapa konsep sebagai pedoman untuk menjawab permasalahan yang dibahas dalam penelitian ini. Konsep yang dimaksud meliputi konsep promosi pariwisata dan konsep strategi pemasaran oleh Hasan (2015), konsep pariwisata oleh Yoeti (1996), konsep wisatawan oleh Pitana (2009), dan konsep klasifikasi wisatawan menurut Ismayanti (2010).

\section{METODE}

Data yang digunakan dalam penelitian ini bersumber dari data primer dan data sekunder. Data primer penelitian ini adalah data yang diperoleh langsung di lapangan serta hasil wawancara mendalam (in-depth interview) dengan para informan. Data primer meliputi informasi mengenai gambaran tentang strategi pemasaran yang diterapkan oleh pengelola Bali Treetop Adventure Park. Sedangkan sumber data sekunder dalam penelitian ini data yang bersumber dari studi kepustakaan seperti buku-buku atau literatur yang berhubungan dengan strategi pemasaran, informasi umum mengenai profil Bali Treetop Adventure Park, dan media elektronik (internet).

Teknik pengumpulan data yang dilakukan dalam penelitian ini menggunakan observasi menurut Kusmayadi dan Sugiarto (2014), wawancara mendalam dan penyebaran kuesioner menurut Sugiyono (2014), dan dokumentasi menurut Creswell (2012). Observasi dalam Kusmayadi dan Sugiarto (2000) merupakan "cara pengumpulan data dengan menggunakan jalan mengamati, meneliti, atau mengukur kejadian yang sedang berlangsung untuk memperoleh data faktual dan aktual menggunakan penginderaan". Observasi dilakukan untuk mengetahui situasi dan kondisi Bali Treetop Adventure Park saat kegiatan wisata berlangsung serta betukbentuk strategi promosi yang mereka terapkan. 
Wawancara mendalam dalam Sugiyono (2014) merupakan "teknik pengumpulan data dimana pewawancara (peneliti atau yang diberi tugas melakukan pengumpulan data) dalam mengumpulkan data mengajukan suatu pertanyaan kepada yang diwawancarai". Dalam hal ini wawancara dilakukan dengan para pengelola Bali Treetop Adventure Park. Wawancara ini dilakukan untuk mengetahui strategi promosi yang digunakan Bali Treetop Adventure Park. Penyebaran kuesioner diajukan kepada wisatawan dengan tujuan untuk mengetahui dari mana wisatawan mendapatkan informasi mengenai Bali Treetop Adventure Park.

Dokumentasi merupakan teknik pengumpulan data untuk menperoleh data dari dokumen-dokumen. Dalam Creswell (2012) dijelaskan bahwa "selama proses penelitian, peneliti bisa mengumpulkan dokumendokumen kualitatif berupa dokumen publik (seperti koran, makalah, laporan kantor) ataupun dokumen privat (seperti buku harian, diary, surat, e-mail)". Dari definisi tersebut dapat disimpulkan bahwa dokumentasi adalah cara memperoleh data dengan mempelajari atau mencatat dari dokumen-dokumen dan arsip yang berhubungan dengan objek penelitian. Dalam penelitian ini, yang termasuk dalam dokumentasi adalah data tentang bentuk-bentuk promosi yang diterapkan oleh Bali Treetop Adventure Park, jurnal penelitian yang terkait dengan fokus penelitian yakni strategi promosi, dan foto-foto penelitian.

Teknik analisis data menggunakan analisis data kualitatif yang dikemukakan oleh Miles dan Huberman dalam Sugiyono (2014). Aktivitas dalam analisis data kualitatif dilakukan secara interaktif dan berlangsung terus menerus sejak pengumpulan data sampai selesai, hingga datanya jenuh. Tahapan analisis tersebut meliputi reduksi data, penyajian data, serta verifikasi atau penarikan kesimpulan. Analisis deskriptif kualitatif dilakukan untuk mengetahui strategi promosi yang diterapkan oleh Bali Treetop Adventure Park.

\section{HASIL DAN PEMBAHASAN}

\section{a. Gambaran Umum Bali Treetop Adventure Park}

Bali Treetop Adventure Park didirikan pada Tahun 2007 oleh Chistoper Jorrad.
Chistoper Jorrad adalah seorang insinyur peralatan outbond dan pengembang kereta layang di Perancis. Perusahaan memiliki nama yang terkenal di wisatawan mancanegara. Bali Treetop Adventure Park berlokasi di Kebun Raya Eka Karya Bali yang terletak di kawasan Bedugul dan dirancang khusus untuk permainan yang menantang selama 2,5 jam. Bali Treetop Adventure Park menyediakan sebanyak 95 macam tantangan permainan yang mendebarkan. Bali Treetop Adventure Park adalah perusahaan yang mempunyai peluang besar menarik wisatawan lokal maupun mancanegara karena Bali Treetop Adventure Park adalah satu satunya di Bali yang memiliki tempat outbond yang sangat luas dan berada di dalam Kebun Eka Karya, Bedugul.

Bali Treetop Adventure Park adalalah taman bermain yang diperuntukkan untuk segmen anak-anak umur 8 sampai orang dewasa umur 72 tahun. Awal mulanya Bali Treetop Adventure Park ini diperuntukkan untuk outing staff hotel dan perusahaan yang mempunyai karyawan lebih dari 90 orang. Treetop di Bali merupakan satu-satunya perusahaan yang bergerak dibidang adventure diatas pohon yang sangat menyenangkan. Target dari perusahaan ini adalah wisatawan asing dari Australia dan wisatawan lokal. Bali Treetop Adventure Park ini memiliki cabang dibeberapa kota di Indonesia yaitu di Yogyakarta dan Bandung.

\section{b. Strategi Promosi Bali Treetop Adventure Park}

Strategi pemasaran merupakan langkah-langkah yang dilakukan oleh suatu perusahaan untuk mencapai tujuan pemasaran. Strategi yang akan dibahas meliputi perumusan strategi promosi, implementasi strategi promosi, dan evaluasi strategi promosi.

\section{Perumusan Strategi Promosi}

Perumusan strategi dalam penelitian ini meliputi langkah-langkah yang dilakukan sebelum menerapkan bentuk-bentuk promosi oleh Bali Treetop Adventure Park. Perumusan strategi promosi yang dimaksud meliputi pemilihan pasar, perencanaan produk, penetapan harga, dan promosi produk. 


\section{Pemilihan Pasar}

Berdasarkan karakteristik wisatawan yang berkunjung ke Bali Treetop Adventure Park, wisatawan lokal dan wisatawan asing asal Australia yang mendominasi. Umumnya mereka merupakan wisatawan yang datang dengan rombongan dan menyukai petualangan. Maka dari itu, Bali Treetop Adventure Park menjadikan wisatawan lokal dan wisatawan asing asal Australia sebagai target pasar utama atau sasaran utama dalam strategi promosi yang diterapkan.

\section{Perencanaan Produk}

Bali Treetop Adventure Park hanya memiliki satu paket produk yang terdiri dari tujuh adventure circuits. Masing-masing adventure circuits tersebut memiliki produkproduk yang menantang dan berbeda dari segi jenis dan ketinggian. Produk yang ditawarkan sebagian besar berada di atas pohon dengan kisaran ketinggian antara 2-20 meter. Total produk yang dimiliki adalah 95 macam tantangan permainan untuk semua level dan umur seperti Suspended Bridges, Spider Nets, Tarzan Jumps, Flying-Fox, Flying Swings, dan masih banyak lagi tantangan yang menyenangkan. Bali Treetop Adventure Park juga memiliki 12 flying fox dengan panjang sampai dengan 160 meter.

Produk yang dimiliki oleh Bali Treetop Adventure Park semuanya merupakan wahana permainan yang dirancang untuk memacu adrenalin dari para pemain baik untuk pemula maupun profesional. Disamping itu, produkproduk yang tersedia di Bali Treetop Adventure Park tidak dimiliki oleh tempat-tempat wisata lain sehingga tempat ini menjadi satu-satunya lokasi di Bali yang dapat dimanfaatkan untuk kegiatan outbond bersama teman atau keluarga. Dengan demikian, Bali Treetop Adventure Park memiliki keunggulan dari segi ketersediaan produk. Produk-produk sebanyak 95 macam tersebut yang akan dipromosikan baik secara langsung, melalui media massa, dan juga secara tidak langsung.

\section{Penetapan Harga}

Tabel 4.1 Daftar Harga Tiket Masuk Wisatawan Asing

\begin{tabular}{c|l|c|c}
\hline \multirow{2}{*}{ No } & \multicolumn{1}{|c|}{ Category } & $\begin{array}{c}\text { Price } \\
\text { (Before } \\
\mathbf{1 0 . 3 0} \\
\text { a.m.) }\end{array}$ & $\begin{array}{c}\text { Price } \\
\text { (After } \\
\mathbf{1 0 . 3 0} \\
\text { a.m.) }\end{array}$ \\
\hline 1 & $\begin{array}{l}\text { Adult } \\
\text { Children (up to 12 } \\
2\end{array}$ & US\$ 25 & US\$ 28 \\
& $\begin{array}{l}\text { U.O) } \\
\text { Family (2 Adult + } \\
\text { up to 2 Children) }\end{array}$ & US\$ 65 & US\$ 18 \\
& US\$ 73 \\
\hline
\end{tabular}

Sumber : Hasil Penelitian, 2016

Berdasarkan Tabel 4.1 diketahui harga untuk pengunjung dewasa asing adalah US\$ 25 sebelum pukul 10.30 a.m. dan US\$ 28 setelah pukul 10.30 a.m. Bagi pengunjung anak-anak asing dengan umur maksimal 12 tahun dikenakan harga US\$ 16 sebelum pukul 10.30 a.m. dan US\$ 18 setelah pukul 10.30 a.m. Untuk family asing dengan rincian 2 pax dewasa dan 2 pax anak-anak dikenakan biaya sebesar US\$ 65 sebelum pukul 10.30 a.m. dan US\$ 73 setelah pukul 10.30 a.m.

Tabel 4.2 Daftar Harga Tiket Masuk Wisatawan Lokal

\begin{tabular}{|c|c|c|c|}
\hline No & Category & $\begin{array}{c}\text { Price } \\
\text { (Before } \\
\text { 10.30 a.m.) }\end{array}$ & $\begin{array}{c}\text { Price } \\
\text { (After } \\
\text { 10.30 a.m.) }\end{array}$ \\
\hline 1 & Adult & Rp 210.000 & $\begin{array}{c}\mathrm{Rp} \\
\end{array}$ \\
\hline 2 & $\begin{array}{l}\text { Children (up } \\
\text { to } 12 \text { Y.O) }\end{array}$ & Rp 110.000 & $\begin{array}{c}\mathrm{Rp} \\
125.000\end{array}$ \\
\hline 3 & $\begin{array}{l}\text { Family } \\
\text { Adult }+ \text { up to } \\
2 \text { Children }\end{array}$ & Rp 525.000 & $\begin{array}{c}\mathrm{Rp} \\
580.000\end{array}$ \\
\hline
\end{tabular}

Sumber : Hasil Penelitian, 2016

Berdasarkan Tabel 4.2 diketahui harga untuk pengunjung dewasa lokal adalah $\mathrm{Rp}$ 210.000 sebelum pukul 10.30 a.m. dan Rp 230.000 setelah pukul 10.30 a.m. Bagi pengunjung anak-anak domestik dengan umur maksimal 12 tahun dikenakan harga $\mathrm{Rp}$ 110.000 sebelum pukul 10.30 a.m. dan Rp 125.000 setelah pukul 10.30 a.m. Untuk family lokal dengan rincian 2 pax dewasa dan 2 pax anak-anak dikenakan biaya sebesar Rp 525.000 sebelum pukul 10.30 a.m. dan Rp 580.000 setelah pukul 10.30 a.m.

Bali Treetop Adventure Park juga memiliki harga kerjasama dengan pihak lain seperti travel agent, komisi untuk guide yang 
membawa wisatawan dan media penjualan online seperti Trip Advisor yaitu dengan memberikan potongan harga $10 \%$ lebih murah dari harga publish.

\section{Promosi Produk}

Promosi Produk yang dilakukan oleh Bali Treetop Adventure Park meliputi promosi langsung, promosi media massa, dan promosi tidak langsung.

\section{A. Promosi Langsung}

1. Sales Call

Sales call adalah kegiatan presentasi produk kepada mitra usaha seperti travel agent untuk melakukan kerjasama. Biasanya dilakukan semingu sekali.

\section{Exhibition}

Exhibition merupakan suatu bentuk dalam usaha jasa pertemuan yang mempertemukan antara produsen dan konsumen. Bali Treetop Adventure Park rutin mengikuti TTC Travel Mart Exhibition yang diselenggarakan setahun sekali di kota-kota besar seperti Jakarta dan Surabaya.

3. Brosur

Brosur ini berisi tentang sekilas informasi Bali Treetop Adventure Park dan informasi harga.

B. Promosi Media Massa

\section{Magazine}

Bali Treetop Adventure Park bekerja sama dengan salah satu media massa ternama di Bali yakni NOW Bali dalam mempromosikan produk yang dimilikinya.

2. Baliho

Bali Treetop Adventure Park melakukan promosi melalaui pemasangan baliho di pinggir jalan di daerah Bedugul menuju lokasi Kebun Raya Eka Karya.

3. Facebook

Bali Treetop Adventure Park aktif melakukan promosi melalui media sosial Facebook dengan mengunggah foto-foto kegiatan yang ada di Bali Treetop Adventure Park.

4. Youtube Bali Treetop Adventure Park melakukan promosi dengan mengunggah beberapa video tentang kegiatan yang dilakukan di Bali Treetop Adventure Park.

\section{Promosi Tidak Langsung}

Promosi tidak langsung yang dilakukan oleh Bali Treetop Adventure Park ini adalah melalui travel agent dan guide lokal dengan cara memberikan harga $10 \%$ lebih rendah dari harga normal.

\section{Implementasi Strategi Promosi}

\section{A. Promosi Langsung}

\section{Sales call}

Sales call ini seharusnya dilakukan sekali dalam seminggu oleh marketing Bali Treetop Adventure Park namun dari hasil wawancara dengan Manajer Operasional dan Marketing Bali Treetop Adventure Park diketahui bahwa sales call yang dilakukan oleh marketing hanya dilakukan sekali dalam sebulan.

2. Exhibition

Exhibition ini rutin diikuti sekali dalam setahun oleh Bali Treetop Adventure Park pada acara TTC Travel Mart yang sering diadakan di kota-kota besar seperti Jakarta dan Surabaya.

3. Brosur

Media brosur ini digunakan Bali Treetop Adventure Park untuk menjangkau semua kalangan karena brosur ini disebarkan di beberapa tempat informasi wisata Bali.

B. Promosi Media Massa

1. Magazine

Bali Treetop Adventure Park bekerja sama dengan Magazine NOW Bali dalam mempromosikan produk yang dimilikinya. Magazine NOW Bali bisa didapatkan di Bandara dan beberapa hotel ternama di Bali.

2. Baliho

Bali Treetop Adventure Park melakukan promosi melalui pemasangan baliho di pinggir jalan di daerah Bedugul menuju lokasi Kebun Raya Eka Karya. Itu adalah satu-satunya baliho yang dimiliki oleh Bali Treetop Adventure Park.

3. Facebook

Facebook menjadi media promosi yang sangat aktif dijalankan oleh Bali Treetop Adventure Park. Mereka sering sekali mengunggah foto-foto dan video kegiatan yang dilakukan yang berlangsung di Bali Treetop Adventure Park. 
4. Youtube

Bali Treetop Adventure Park mengunggah beberapa video di youtube namun dari hasil wawancara diketahui bahwa media ini tidak begitu diperhitungkan oleh pihak Bali Treetop Adventure Park.

C. Promosi Tidak Langsung

Bali Treetop Adventure Park melakukan kerjasama dengan beberapa travel agent seperti Buffalo Tours, Bali Reservasi Tours, Pacto Tours dan TMS Tour. Selain travel agent tersebut guide lokal juga memberikan kontribusi yang cukup besar untuk membawa wisatawan yang besar dengan cara komunikasi langsung.

\section{Evaluasi Strategi Promosi}

Penyebaran kuesioner dilakukan untuk mengetahui dari mana wisatawan mengetahui Bali Treetop Adventure Park. Adapun hasilnya dapat dilihat pada Tabel 4.3 :

Tabel 4.3 Sumber Informasi

\begin{tabular}{c|l|c|c}
\hline No & \multicolumn{1}{|c|}{$\begin{array}{c}\text { Sumber } \\
\text { Informasi }\end{array}$} & $\begin{array}{c}\text { Jumlah } \\
\text { (Orang) }\end{array}$ & $\begin{array}{c}\text { Persentas } \\
\text { e (\%) }\end{array}$ \\
\hline 1 & Word of Mouth & 16 & 22.9 \\
2 & (WOM) & 6 & 8.6 \\
3 & Trosur & 23 & 32.9 \\
4 & Facebook & 18 & 25.8 \\
5 & Youtube & 1 & 1.4 \\
6 & Guide Books & 1 & 2.8 \\
7 & Website & 1 & 1.4 \\
8 & Magazine & 2 & 2.4 \\
9 & Other & 70 & 100 \\
\hline \multicolumn{2}{|c}{ TOTAL }
\end{tabular}

Sumber : Hasil Penelitian, 2016

Berdasarkan Tabel 4.3 diketahui bahwa

dari 70 wisatawan sebanyak $32.9 \%$ mendapatkan informasi dari Trip Advisor, diikuti Facebook sebesar 25.8\%, dan Word of Mouth (WOM) sebesar 22.9\%. Angka tersebut menunjukkan bahwa promosi media massa dan promosi tidak langsung memberikan kontribusi yang sangat besar dibandingkan dengan media promosi lainnya.

Dari media promosi yang digunakan oleh Bali Treetop Adventure Park, seluruhnya adalah untuk menjaring target pasar yang sudah ditetapkan yaitu wisatawan asing dari
Australia dan wisatawan domestik, sebagaimana dijelaskan pada Tabel 4.4 :

Tabel 4.4 Asal Wisatawan

\begin{tabular}{c|l|c|c}
\hline $\begin{array}{c}\text { N } \\
\mathbf{o}\end{array}$ & \multicolumn{1}{|c|}{ Asal } & $\begin{array}{c}\text { Jumlah } \\
\text { (Orang) }\end{array}$ & $\begin{array}{c}\text { Persentase } \\
\text { (\%) }\end{array}$ \\
\hline 1 & Australia & 29 & 41.5 \\
2 & Indonesia & 20 & 28.6 \\
3 & Cina & 2 & 2.8 \\
4 & Belanda & 2 & 2.8 \\
5 & UK & 2 & 2.8 \\
6 & USA & 3 & 4.3 \\
7 & Others & 12 & 17.2 \\
\hline \multicolumn{2}{|c}{ TOTAL } & 70 & 100 \\
\hline
\end{tabular}

Sumber : Hasil Penelitian, 2016

Berdasarkan Tabel 4.4 diketahui bahwa dari 70 wisatawan sebanyak $41.5 \%$ adalah wisatawan asing dari Australia, diikuti Indonesia sebesar $28.6 \%$, other sebesar $17.2 \%$. Angka tersebut menunjukkan bahwa strategi promosi Bali Treetop Adventure Park sudah mencapai target pasar yang dituju.

Bali Treetop Adventure Park beroperasi dari tahun 2013 sampai tahun 2016 namun strategi promosi menembus angka $100 \%$ atau memenuhi target dimulai pada akhir tahun 2013 hingga 2016. Tetapi manajemen Bali Treetop Adventure Park masih belum teratur dalam menerapkan strategi promosi sehingga ke depan perlu dilakukan evaluasi agar menjadi lebih baik dan menjaga target promosi selalu berada di titik optimal.

\section{SIMPULAN DAN SARAN}

Bali Treetop Adventure Park memiliki beberapa strategi promosi yaitu promosi langsung (sales call, exhibition, brosur), promosi media massa (magazine, baliho, facebook, youtube), dan promosi tidak langsung (travel agent dan local guide). Strategi promosi yang dimiliki Bali Treetop Adventure Park ini bertujuan untuk menjaring target pasar yang telah ditentukan sebelumnya yaitu wisatawan mancanegara dari Australia dan wisatawan lokal.

Wisatawan mancanegara dari Australia dan wisatawan lokal sebagai target pasar utama terbukti mampu terserap cukup banyak yakni sebesar 70\% dari keseluruhan wisatawan. Ini menunjukkan bahwa target pasar Bali Treetop Adventure Park sudah mencapai target. Ada perbedaan harga antara wisatawan 
mancanegara antara dan lokal yaitu US\$ 28 untuk wisatawan mancanegara dan Rp 230.000 atau sekitar US\$23 untuk wisatawan lokal.

Dari keseluruhan strategi promosi yang dimiliki Bali Treetop Adventure Park, promosi media massa melalui Trip Advisor dan Facebook yang memberikan kontribusi paling besar untuk mendatangkan wisatawan. Disamping itu Word of Mouth (WOM) juga tidak kalah dalam memberikan kontribusi untuk mendatangkan wisatawan.

Adapun saran yang dapat diberikan kepada pihak pengelola Bali Treetop Adventure Park untuk memaksimalkan strategi promosinya adalah :

1. Selalu memperbarui konten-konten pada media massa Facebook.

2. Memperbaiki kinerja nyata di lapangan agar mendapatkan citra yang baik di Trip Advisor.

3. Mengembangkan strategi promosi pada media massa dalam bentuk media sosial terbaru seperti Instagram dan Twitter.

Bagi pihak akademisi yang ingin melakukan penelitian selanjutnya diharapkan untuk mendalami aspek strategi pemasaran lainnya.

\section{DAFTAR PUSTAKA}

Creswell, John W. 2012. Research Design Pendekatan Kualitatif, Kuantitatif, dan Mixed. Yogyakarta : Pustaka Pelajar.

Darma, I Dewa Putu. 2009. Kebun Raya "Eka Karya" Bali, Konservasi dan Budaya dalam Harmoni. Jurnal Udayana Mengabdi, Vol 8, No 1.

Guntur, Effendi M. 2010. Transformasi Manajemen Pemasaran + Membangun Cittra Ne gara. Jakarta: CV Sagung Seto.

Hasan, Ali. 2015. Tourism Marketing. Yogyakarta : CAPS.

Ismayansi. 2010. Pengantar Pariwisata. Jakarta : PT. Gramedia Widisarana.

Kusmayadi dan Sugiarto, Endar. 2000. Metodologi Penelitian dalam Bidang Kepariwisataan. Jakarta : PT. Gramedia Pustaka Utama.

Pitana, I Gde dan I Ketut Surya Diarta. 2009. Pengantar Ilmu Pariwisata. Yogyakarta : ANDI.

Pitana, I Gde. 2016. Presentasi "Tantangan dan Antisipasi Pembangunan Bali ke Depan", Bali Update 2016.

Sugiyono. 2014. Metode Penelitian Kuantitatif, Kualitatif, dan R\&D. Bandung : Alfabeta.

Weaver, David B. 2001. The Encyclopedia of Ecotourism. Wallingford : CABI Publishing.

Yoeti, Oka A. 1996. Pengantar Ilmu Pariwisata. Bandung : Angkasa.

Zahro, Dewi Fatikhatuz. 2012. Strategi Komunikasi Pemasaran Terpadu Desa Wisata dalam Meningkatkan Kunjungan Wisatawan (Studi Deskriptif Kualitatif pada Desa Wisata Kelor,
Sleman, Yogyakarta). Laporan Akhir Program Studi Ilmu Komunikasi Universitas Islam Negeri Sunan Kalijaga. 